\title{
História da Matemática em Vídeos: Uma Produção Acerca da Origem das Geometrias Não Euclidianas
}

\author{
History of Mathematics in Videos: A Production About the Origin of Non-Euclidean
}

Geometries

Lucas Ferreira Gomes ${ }^{1}$

Eliane Maria de Oliveira Araman ${ }^{2}$

\section{Resumo}

Reconhecendo que o avanço das tecnologias tem influenciado o modo como as pessoas pensam, se comunicam, adquirem informação, entre tantas outras ações que são inerentes a vida do ser humano, entende-se que a inserção das tecnologias no contexto escolar torna-se, cada vez mais, indispensável. Entre estas tecnologias, pode-se citar as Tecnologias da Informação e Comunicação (TIC) as quais oferecem inúmeros recursos que podem favorecer os processos de ensino e de aprendizagem. Dentre estes recursos pode-se citar os vídeos didáticos, que devido às suas diversas linguagens e ferramentas é possível explorar diversos conceitos de forma objetiva e lúdica. Além disso, a História da Matemática caracteriza-se como recurso didático que pode contribuir para compreensão dos conceitos matemáticos, a partir de uma reflexão dos elementos históricos que possibilitaram estes conceitos surgirem. Desta forma, defendemos que é possível aliar os vídeos didáticos a História da Matemática e, assim, este trabalho tem como objetivo propor uma forma de se elaborar vídeos didáticos baseados na História da Matemática que podem ser explorados em sala de aula. Para tanto, apresentaremos esta proposta por meio de uma exemplificação: a produção de um vídeo que explora a origem das geometrias não euclidianas, destacando os passos que foram seguidos até a elaboração final desse vídeo.

Palavras-chave: História da Matemática; Vídeos didáticos; Geometrias não euclidianas; Educação Matemática.

\section{Introdução}

Percebe-se que o ensino da Matemática nas escolas brasileiras tem enfrentado momentos difíceis, a exemplo disto tem-se as avaliações nacionais e

\footnotetext{
${ }^{1}$ Mestre, professor, Universidade Tecnológica Federal do Paraná, lucasgomis@hotmail.com

${ }^{2}$ Doutora, professora, Universidade Tecnológica Federal do Paraná, elianearaman@utfpr.edu.br
} 
internacionais que apontam baixos índices de nossos estudantes em relação a Matemática (OLIVEIRA, 2013). A exemplo, os resultados do último $\mathrm{PISA}^{3}$ (2015) apontam que a média dos alunos caiu de 391 para 377 pontos, além de estar longe do primeiro colocado, Cingapura com 564 pontos. Os problemas que afetam o rendimento destes alunos são muitos, como falta de estrutura, falta de materiais, formação de professores, entre tantos outros problemas que influenciam direta e indiretamente na aprendizagem (OLIVEIRA, 2013).

Desta forma, cabe a Educação Matemática e seus pesquisadores buscar alternativas e meios para mudar esse quadro, como pensar em estratégias diferenciadas que podem ser exploradas em sala de aula, propiciar formação continuada para professores que atuam na Educação Básica, elaborar jogos e materiais que auxiliem na compreensão dos conceitos matemáticos, entre tantas ações que podem ser desempenhadas por esta área de conhecimento, a qual tem como um de seus focos de estudo o ensino e a aprendizagem da Matemática.

Dentre os problemas que tem influenciado na aprendizagem dos estudantes, Deixa e Salvi (2014) destacam que a Matemática apresentada a eles no contexto escolar, na maioria das vezes, é desvinculada de sua origem e de seus aspectos históricos, enfatizando-se os procedimentos e técnicas matemáticas, ao invés de uma reflexão sobre o surgimento destes conceitos. Neste sentido, torna-se necessário propor estratégias que possibilitem aos educandos compreender como e quando estes conceitos surgiram, mostrando que a Matemática não é uma ciência pronta e acabada, mas que muitos conceitos surgiram em momentos diferentes e que ainda estão surgindo, e, em muitos casos, na tentativa do homem de resolver seus problemas (BRASIL, 1997).

Neste contexto, emerge a História da Matemática como um recurso didático que pode possibilitar uma compreensão substantiva dos conceitos matemáticos, pelo fato de poder conduzir o aluno a entender as razões

\footnotetext{
${ }^{3}$ Programa Internacional de Avaliação de Alunos - é uma avaliação internacional que mede o nível educacional de jovens de 15 anos por meio de provas de Leitura, Matemática e Ciências. $\mathrm{O}$ objetivo principal do Pisa é produzir indicadores que contribuam, dentro e fora dos países participantes, para a discussão da qualidade da educação básica e que possam subsidiar políticas nacionais de melhoria da educação.
} 
matemáticas, bem como os conceitos e os seus desenvolvimentos. Esse recurso didático se caracteriza como uma fonte de investigação para as aulas de Matemática, que pode atrair os educandos, levando-os a reconhecer que todo conhecimento tem sua história, e que a Matemática é uma construção humana (GROENWALD, 2004). Assim, entende-se que a História da Matemática é uma das alternativas para que a melhora da aprendizagem da Matemática na Educação Básica aconteça.

É neste contexto que o presente trabalho se insere, o qual tem como objetivo propor uma forma de se elaborar vídeos didáticos baseados na História da Matemática que podem ser explorados em sala de aula. Sendo os vídeos uma das formas de se inserir os aspectos históricos dos conceitos matemáticos nas aulas de Matemática.

O uso dos vídeos didáticos se deve ao fato de que se pode "buscar apoio na História da Matemática para escolher métodos pedagogicamente adequados e interessantes para abordar determinados tópicos. Um destes métodos pode ser o vídeo" (MACHADO, 2011, p. 16). Seu uso reside no fato de que os vídeos em sua linguagem audiovisual utiliza-se de diversos recursos como visual, musical, linguagem falada e a escrita, os quais não são separados, mas interligados que podem atingir o imaginário de quem vê (MACHADO; MENDES, 2013), contribuindo, assim, para compreensão dos conceitos nele explorado.

Por fins didáticos, apresentaremos nossa ideia para elaboração de vídeos didáticos baseados na História da Matemática por meio de uma exemplificação: a elaboração de um vídeo que explora a origem das geometrias não euclidianas.

\section{A História da Matemática no Contexto do Ensino da Matemática}

Favuel e Maanen (2000) destacam que a Matemática precisa ser entendida como empreendedorismo humano, como fruto do pensamento humano, que vem sendo desenvolvido ao longo da história da humanidade. Segundo eles, a partir 
do uso da História da Matemática na Educação Matemática, devido as suas potencialidades pedagógicas para o ensino, é possível alcançar tais entendimentos. Neste estudo os autores buscam explicitar o papel que ela desempenha no processo de ensino e de aprendizagem e para eles "matemáticos, historiadores e educadores de muitos países pensam, já há algum tempo, que a Educação Matemática pode ser melhorada, de alguma forma, pela incorporação da História da Matemática" (FAVUEL; MAANEM, 2000, p. 13, apud ARAMAN, 2011).

Indo ao encontro desta perspectiva, Katz (2008 - apud BISSI, 2015, p. 4) destaca que esta deve ser inserida nas aulas de Matemática pelo fato de que "é necessário apresentar aos alunos o desenvolvimento das ideias matemáticas, mostrando como a Matemática foi constituída de forma natural e que as ideias dos grandes matemáticos perduram até os dias atuais". Chaquiam (2015, p. 13) corrobora ao afirmar que os:

[...] estudos atuais apontam que a História da Matemática, combinada com outros recursos didáticos e metodológicos, pode contribuir para a melhoria do ensino e da aprendizagem da Matemática, emerge como uma possibilidade de buscar uma nova forma de ver e entender a Matemática, tornando-a mais contextualizada, mais integrada com as outras disciplinas.

Para tanto, é necessário entender que para a melhor compreensão da Matemática, em seu desenvolvimento atual, é importante considerar todo o processo com suas transformações e intenções de cada época e civilização. Por isso, de acordo com Jankvist (2009), a História da Matemática pode levar o aluno a entender como a Matemática evoluiu, como e quando os conteúdos foram surgindo e, também, o contexto no qual se deu a criação destes.

Neste viés, este recurso didático apresenta-se como uma possibilidade de se trabalhar os afetos envolvidos nos processos de ensino e de aprendizagem de maneira positiva, podendo colaborar para a quebra do ciclo de exclusão em relação a Matemática escolar. Pois, o aluno, ao tomar o contato com as produções matemáticas de diferentes épocas e culturas, pode ressignificá-la e estabelecer uma atividade dialógica com as diferentes características da 
linguagem Matemática, que, de acordo com Machado (2011), não se manifestam no conhecimento construído na escola. Este autor também ressalta que a Matemática explorada em sala de aula, na atualidade, se monstra desvinculada dos seus contextos históricos, sociais e culturais, o que pode trazer prejuízos à aprendizagem dos alunos.

Desta forma, a História da Matemática apresenta-se como das diversas possibilidades de se modificar o ensino da Matemática na Educação Básica, pois pode desempenhar inúmeros contributos para o ensino dessa ciência, não só para formação do aluno, mas também a prática docente pode ser reforçada e/ou melhorada a partir dela (ARAMAN, 2011).

\section{Os Vídeos Didáticos e sua Relação com a História da Matemática}

Cada vez mais, as tecnologias têm integrado a vida do ser humano, a medida que os meios de aquisição de informação, bem como as formas de comunicação tem se modificado, influenciando diretamente na forma como as pessoas pensam e agem, surgindo assim a sociedade da informação.

Compreende-se, assim, que, cada vez mais, a inserção das tecnologias no contexto escolar seja algo necessário, a fim de atender as necessidades dessa nova sociedade. Indo ao encontro desse pensamento, Baldin (2008, p. 7) afirma que os recursos tecnológicos têm desempenhado inúmeras influências na prática educacional, principalmente na disciplina de Matemática. Neste contexto, a produção e o uso de vídeos didáticos tem se mostrado como uma das alternativas para inserção dos recursos digitais em sala de aula, que devidos as suas potencialidades pode contribuir para aprendizagem de Matemática. Segundo Carvalho e Gonçalves (2000, p. 17), "as imagens do vídeo causam impacto e falam por si mesmas". Além de possuir uma dimensão moderna e lúdica (MORÁN, 1995). 
Dentre estes recursos, emerge o vídeo didático o qual pode desempenhar um importante papel em sala de aula. Uma grande vantagem de seu uso é que os jovens estão acostumados como ele, isto é, o vídeo é uma mídia cada vez mais presente no cotidiano dos alunos, mas como uma forma de entretenimento e que quando inserido nas aulas pode funcionar como um elemento auxiliador da aprendizagem. Seguindo esta ideia, Morán (1995, p. 27-28) afirma que:

O vídeo está umbilicalmente ligado à televisão e a um contexto de lazer, de entretenimento, que passa imperceptivelmente para a sala de aula. Vídeo, na concepção dos alunos, significa descanso e não "aula", o que modifica a postura e as expectativas em relação ao seu uso. Precisamos aproveitar essa expectativa positiva para atrair o aluno para os assuntos do nosso planejamento pedagógico. Mas, ao mesmo tempo, saber que necessitamos prestar atenção para estabelecer novas pontes entre 0 vídeo e as outras dinâmicas da aula (MORÀN, 1995, p. 27-28).

Assim, entende-se que o vídeo enquanto recurso didático pensado e inserido com objetivos pedagógicos pré-definidos pode trazer algumas corroborações. Permite ao aluno ver como uma história aconteceu. Quando usado para aumentar a memória visual é uma ferramenta valiosa. O vídeo pode atingir as crianças com uma grande variedade de estilos de aprendizagem. Pode trazer novas informações para sala de aula. Ela pode servir para expor aos estudantes informações, pessoas, lugares e eventos que outros recursos de aprendizagem não podem (MACHADO, 2011).

Segundo Cury e Motta (2008), Machado (2011), Machado e Mendes (2013), entre outros pesquisadores, devido as potencialidades desse recurso ele pode ser aliado a outros recursos didáticos, dentre eles a História da Matemática. Neste contexto, Machado (2011, p. 63) apresenta a seguinte ponderação:

[...] defendemos a utilização de instrumentos tecnológicos como ferramentas de mediação dos conceitos matemáticos abordados através da História da Matemática, como o vídeo, por exemplo, mas outras formas de mídia podem ser usadas e manipuladas tanto por professores como por alunos.

Eles destacam que é possível aliar a História da Matemática aos vídeos didáticos, isto é, é possível explorar a partir dos vídeos elementos históricos dos 
conceitos matemáticos, que pode propiciar uma compreensão dos conceitos que neles são explorados. Para tanto, Costa $(2015$, p. 5) defende que:

Para o resgate histórico dessa disciplina o professor pode realizá-lo por narrativas dos fatos ou pode apresentá-los em forma de vídeo. A popularização dos recursos de vídeo tem colocado os educadores a refletir sobre o potencial didático-pedagógico do uso dessa mídia em sala de aula. As televisões tornaram-se cada vez mais perfeitas na resolução de imagens. Também os aparelhos de reprodução tiveram seus aprimoramentos, como o vídeo cassete, DVDs... . A medida que a imagem se aperfeiçoa, tanto na transmissão quanto na qualidade de imagem, as produções de documentários, filmes, programas de entrevistas, séries de TV e outras, ganham qualidade e quantidade de unir o filme como um recurso didático ao ensino, sobretudo da Matemática.

Por isso, acreditamos que estes elementos possam ser explorados em vídeos didáticos, sendo esta uma estratégia que pode possibilitar uma compreensão, baseada na reflexão, dos conceitos matemáticos a serem abordados tanto, na Educação Básica, quanto na formação de professores que ensinam Matemática. Como destaca Machado (2011), o qual se propôs a elaborar e aplicar vídeos didáticos baseados em informações históricas acerca da Matemática, a produção de vídeos de História da Matemática é algo possível e podem ser usadas por professores em suas aulas ou em cursos de formação de professores.

\section{Aspectos metodológicos}

Devido às características da presente pesquisa, consideramos a abordagem qualitativa a mais adequada. De acordo com Bogdan e Biklen (1994), uma investigação qualitativa é descritiva e seu interesse maior está no processo e não, apenas, nos resultados obtidos. Outro aspecto destacado por eles é que nem tudo pode ser considerado como trivial, uma vez que "tudo tem potencial para constituir uma pista que nos permita estabelecer uma compreensão mais esclarecedora do nosso objeto de estudo" (BOGDAN; BIKLEN, 1994, p. 43). 
No intuito de mostrar que é possível explorar vídeos didáticos baseados em aspectos históricos de conceitos matemáticos, apresentaremos neste trabalho uma possibilidade de se produzir vídeos com tais características, isto é, uma estratégia para se elaborar este tipo de vídeo. Para tanto, faremos isso por meio de uma exemplificação destacando os passos utilizados na elaboração de um vídeo que explora a origem das geometrias não euclidianas, dando destaque as geometrias hiperbólica e elíptica, desde Euclides de Alexandria aos principais matemáticos que fizeram tamanha criação.

Para elaboração deste, seguimos alguns passos os quais foram:

O primeiro passo foi a construção dos aspectos teóricos que norteiam a presente proposta, sendo elas as pesquisas que versam sobre a História da Matemática, o uso de vídeos didáticos e os saberes docentes.

Já o segundo passo foi o recorte do episódio histórico no qual o vídeo se baseia, destaca-se que este foi desenvolvido a partir dos saberes docentes apresentados por Tardif (2013), especificamente a partir dos saberes da formação docente, dos saberes curriculares e dos saberes disciplinares, os quais possibilitaram desenvolver uma justificativa para o recorte realizado.

Em relação ao terceiro passo foi a elaboração do roteiro ou script desenvolvido a partir do episódio histórico recortado, transformando tal episódio em estrutura de vídeo.

No quarto passo foi feita a construção da animação partir do software Powerpoint, desenvolvida a partir do roteiro, inserindo as imagens, textos, cenários entre outros elementos que serão apresentados mais adiante.

O quinto e último passo foi realizada a gravação e a edição do vídeo.

Destaca-se que estes três últimos passos foram desenvolvidos seguindo as sugestões para elaboração de vídeos baseados na História da Matemática, proposto por Machado e Mendes (2013). 


\section{Produção do vídeo didático}

$\mathrm{Na}$ busca de encontrar uma forma de se realizar o recorte de um episódio histórico que pudesse ser transformado em vídeo didático, procurou-se levantar na literatura subsídios para elaborar uma estratégia para realizar tal recorte, a partir desta pesquisa encontrou-se nos saberes docentes e suas tipologias, apresentados por Tardif (2013), elementos que possibilitaram fazê-lo.

Discussões que remetem aos saberes mobilizados pelos professores em sua prática pedagógica têm propiciado o desenvolvimento de diversas pesquisas, como Gauthier (2006) e Tardif (2013), entre tantas outras. Esses e outros pesquisadores defendem que a profissionalização da atividade docente deve identificar os saberes próprios do ensino, levando em consideração os contextos em que esses saberes se efetivam, visto que trazem uma marca muito forte para a ação desses sujeitos, influenciando nas tomadas de decisões, bem como nas escolhas realizadas.

Essas pesquisas também remetem a perspectiva de que os saberes docentes "formam uma espécie de reservatório" que o professor pode abastecer para atender as necessidades que a ação docente exige (GAUTHIER, 2006). Neste mesmo viés, Tardif e Gauthier (1996, p. 11) destacam que "o saber docente é um saber composto de vários saberes", os quais são responsáveis pela estruturação do conhecimento dos professores, e, por isso, influenciam em suas práticas. Além desses aspectos, Tardif (2013) apresenta algumas tipologias de saberes docentes, e a partir destas tipologias, foi possível identificar nos saberes da formação pedagógica, nos saberes disciplinares e nos saberes curriculares elementos que possibilitaram realizar o recorte: aspectos relacionados a origem do conteúdo, bem como, orientações curriculares para tal conteúdo, ou seja, conseguimos destacar os seguintes aspectos:

- Os saberes da formação profissional: são constituídos pelas técnicas, métodos, estratégias e recursos que dizem respeito às formas de se ensinar, assim para realizar o recorte do episódio histórico nos orientamos pelos 
aspectos didáticos que a História da Matemática enquanto recurso didático propõe, isto é, antes de se realizar o recorte do episódio buscamos conhecer as orientações da História da Matemática.

- Os saberes disciplinares: este é composto pelo conjunto de conhecimentos adquiridos pelos povos ao longo do tempo, isto é, o próprio conteúdo. Por conseguinte, para realizar o recorte do episódio histórico nos orientamos pelo conteúdo a ser abordado e pelos aspectos históricos desse conteúdo.

- Os saberes curriculares: estes saberes dizem respeito às orientações e/ou propostas curriculares, em suma são os documentos que norteiam a educação. Para tanto, em nosso recorte também nos baseamos no que dizem os documentos norteadores sobre a temática a ser abordada, além disso, julgando se a História da Matemática pode ser empregada no ensino deste tópico e julgar se com ela será possível atingir os objetivos previamente definidos.

Sob tal enfoque, apresenta-se o recorte realizado e sua justificativa seguindo como pressuposto:

- As orientações curriculares: o que defendem as Diretrizes Curriculares de Matemática do Estado do Paraná (2008) e os Parâmetros Curriculares Nacionais de Matemática (1997) a respeito das Geometrias Não Euclidianas e o seu ensino (vinculado aos saberes curriculares).

- Os fundamentos da história: os aspectos históricos das Geometrias Não Euclidianas (vinculado aos saberes disciplinares).

- As orientações metodológicas: o que dizem as pesquisas desenvolvidas sobre os aspectos metodológicos da História da Matemática para o ensino de Matemática (vinculado aos saberes da formação pedagógica).

Com efeito, foi possível sintetizar em um esquema os saberes que julgamos necessários para se realizar o recorte do episódio histórico que pode ser explorado em vídeos didáticos: 
Figura 1 - Saberes empregados no recorte

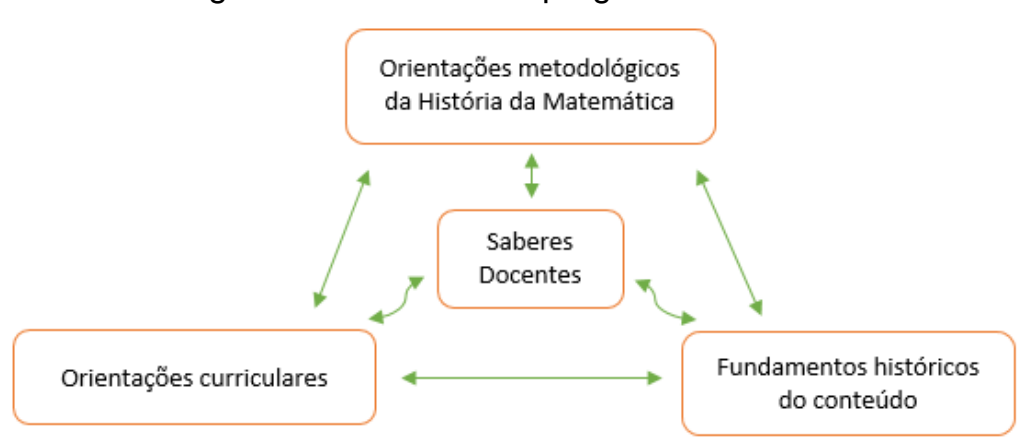

Fonte: Os Autores

\author{
Por meio desta estratégia foi possível realizar o recorte do episódio \\ histórico a partir das reconstruções históricas da origem das Geometrias Não \\ Euclidianas realizadas por Barbosa (2011) e Ribeiro (2012). Segue o recorte, bem \\ como a justificativa para o mesmo:
}

\title{
Quadro 1 - Recorte realizado
}

As geometrias não euclidianas surgiram a partir da própria geometria euclidiana plana, a qual teve como seu grande propulsor Euclides, pouco se sabe sobre ele e muitos duvidam da sua existência, mas de acordo com Nobre (2009), Euclides viveu entre 325 a.C. e 265 a.C. na cidade egípcia de Alexandria, sendo professor da Biblioteca e Museu de Alexandria. Euclides, enquanto professor e pesquisador da Biblioteca, foi autor de uma das maiores obras da Matemática, e um dos textos matemáticos mais importantes da época grega, escrito, há cerca de 2300 anos, chamada de Os Elementos.

Esta obra é uma coleção de treze livros, mas não apresenta uma estrutura unificadas, sendo caracterizada por um compêndio, que foi organizado por Euclides a partir de muitas obras existentes sobre várias áreas da Matemática incluídas no trabalho.

É no primeiro dos treze livros de Os Elementos que se encontram os cinco famosos postulados que deram forma à "Geometria Euclidiana Plana" ou "Geometria Plana". Além disso, ele traz 23 definições e 9 noções comuns. São os postulados:

(1) Pode-se traçar uma (única) reta ligando dois pontos.

(2) Pode-se prolongar (de uma única maneira) uma reta finita continuamente em uma linha reta.

(3) Pode-se traçar um círculo com centro qualquer e raio qualquer.

(4) Todos os ângulos retos são iguais.

(5) Se uma reta, interceptando duas outras, forma ângulos internos de um mesmo lado cuja soma é menor que dois retos, então estas duas retas, se prolongadas indefinidamente, se encontram naquele lado cuja soma dos ângulos internos é menor que dois retos (BICUDO, 2009, p. 98).

O quinto postulado trouxe grandes repercussões entre os matemáticos que se dedicaram a tentar prová-lo, até mesmo por que, segundo Brito (1995), Proclo, um grande comentarista de Os Elementos no século V, percebeu que as 28 primeiras proposições do trabalho (465 no total) são demonstradas sem empregar este postulado, sendo que algumas seriam facilmente demonstradas se o quinto postulado fosse utilizado, isso pode indicar que até Euclides tentava 
"evitar" o uso deste postulado (KATZ, 2011).

Diversos são os matemáticos que tentaram prová-lo, dentre eles: Ptolomeu I, Proclo, o árabe Nasis Eddin All Tusin, John Wallis, o padre jesuíta Girolamo Saccheri (o primeiro a publicar), Joahnn Heinrich Lambet, Adrien Marie Legendre, entre tantos outros (BARBOSA, 2011). Muitos também tentam reescrevê-lo ou criar proposições equivalentes, sendo a mais famosa a proposta por John Playfair (1748-1819), que ficou conhecida como postulado das paralelas, o qual diz que "por um ponto fora de uma reta pode-se traçar uma única reta paralela à reta dada" (BARBOSA, 2011, p. 29).

Apesar de todas as investigações e tentativas, não foi possível prová-lo, porém, séculos mais tarde (XVIII e XIX), alguns matemáticos compreenderam que o quinto postulado de Euclides, além de não poder ser provado, poderia ser negado sem que contradições acontecessem. Neste episódio ganham destaque Nikolay Ivanovich Lobachevsky (1792-1856), János Bolyai (18021860) e Cal Friedrich Gauss (1777-1855), os quais descobrem que, ao negar ou substituir o quinto postulado por outro, surgiria uma nova geometria, tão válida quanto a de Euclides (BARBOSA, 2011). Isso abriu o caminho para que novas geometrias surgissem, e hoje entende-se por geometria não euclidiana, como qualquer geometria que negue pelo menos um dos postulados de Euclides (BRASIL, 1997).

Fonte: Os Autores

Justificativa para o recorte:

- Orientações curriculares: De acordo com as DCE de Matemática (PARANÁ, 2008 , p. 66) uma "abordagem histórica deve vincular as descobertas matemáticas aos fatos sociais e políticos, às circunstâncias históricas e às correntes filosóficas que determinaram o pensamento e influenciaram 0 avanço científico de cada época", que é aquilo que o recorte traz.

- Fundamento histórico: Para Hansem (1998), foi a criação de um ramo novo que mostrou que a geometria de Euclides não era uma verdade incontestável, pensamento que se tinha até aquele momento, desta forma este feito abriu um caminho para as discussões sobre a consistência das diversas áreas da ciência e da própria Matemática.

- Orientações metodológicas: De acordo com Mendes e Chaquiam (2016) devese explorar as histórias relacionadas aos aspectos matemáticos em seu processo de criação, reinvenção e organização lógica, estabelecidos no tempo e no espaço com a finalidade de sistematizar soluções de problemas de ordem sociocultural e científica, em todos os tempos e lugares; e, no que diz respeito às geometrias não euclidianas, Hansem (1998) propõe que inicialmente devese apresentar o contexto histórico que possibilitou estas geometrias surgirem: o quinto postulado de Euclides. 
A partir deste recorte, deu-se inícios a produção do vídeo seguindo os passos propostos por Machado e Mendes (2013) para produção de vídeos didáticos baseados na História da Matemática:

1. Elaboração do título dos vídeos didáticos

"O título a ser dado nos vídeos deve ser fruto da realização de um estudo e pesquisa sobre um determinado tema ou assunto que o represente de uma maneira geral" (MACHADO; MENDES, 2013, p. 95). Portanto, resumir a ideia explorada no vídeo, no caso escolheu-se como título para o vídeo elaborado: "A origem das geometrias não euclidanas".

2. Introdução

"Trata-se na verdade de uma síntese ou resumo do assunto; é uma breve introdução ao foco do assunto e que destaca os aspectos mais importantes. Em suma, é o que vai atrair a atenção inicial dos alunos às vídeo-aulas" (MACHADO; MENDES, 2013, p. 96). Estes autores também destacam que essa introdução deve ser breve.

Assim, optou-se por uma breve saudação, um resumo dos conceitos que seriam explorados e o objetivo do vídeo.

\section{Storyboard}

"Desenho das tomadas e enquadramento de modo que se ajustem as realizações das fases anteriores [...] isso se faz necessário para garantir que as imagens usadas obedeçam àqueles conteúdos de que tratam as vídeo-aulas" (MACHADO; MENDES, 2013, p. 96). Em suma, essa etapa é o planejamento, bem como a organização do vídeo a ser desenvolvido, que neste caso foi a partir do recorte realizado. Para tanto, transformou-se tal recorte no script, que é organização e a estruturação do vídeo: 
Quadro 2 - Roteiro

Aparecer o avatar fazendo esse comentário.

Olá meu nome é Eugênio neste vídeo vamos falar sobre como surgiram um novo universo para a geometria, chamado de geometrias não-euclidianas, assim vamos destacar o que motivou esse surgimento e quem contribuiu para isso.

Falaremos inicialmente sobre Euclides de Alexandria, o propulsor de tudo.

Aparecer a foto de Euclides.

Pouco se sabe sobre Euclides, e muitos duvidam até se ele realmente existiu, todavia muitos estudiosos entendem que Euclides viveu entre 325 a.C. e 265 a.C. na cidade egípcia de Alexandria.

Aparecer o mapa de Alexandria.

Sendo professor da Biblioteca e Museu de Alexandria.

Aparecer a fachada do museu.

Aparecer 0 avatar explicando:

Euclides, enquanto professor e pesquisador da Biblioteca, foi autor de uma das maiores obras da matemática, e um dos textos matemáticos mais importantes da época grega, escrito, há cerca de 2300 anos, chamada de Os Elementos.

Aparecer a foto dos elementos.

Os Elementos de Euclides é uma coleção de treze livros, mas nem tudo o que aparece nessa obra foi descoberto por ele. Sua estrutura interna se caracteriza por um resumo, que foi organizado por Euclides a partir de muitas obras existentes sobre várias áreas da matemática incluída no trabalho.

Aparecer o avatar explicando:

É no primeiro dos treze livros de Os Elementos que se encontra os 5 famosos postulados que deram forma a "Geometria Euclidiana" ou "Geometria Plana", além disso ele traz vinte e três definições e nove noções comuns. Os postulados são:

Aparecer no quadro:

I. Pode-se traçar uma (única) reta ligando dois pontos.

II. Pode-se prolongar (de uma única maneira) uma reta finita continuamente em uma linha reta.

III. Pode-se traçar um círculo com centro qualquer e raio qualquer.

IV. Todos os ângulos retos são iguais.

V. Se uma reta, interceptando duas outras, forma ângulos internos de um mesmo lado cuja soma é menor que dois retos, então estas duas retas, se prolongadas indefinidamente, se encontram naquele lado cuja soma dos ângulos internos é menor que dois retos

Aparecer o avatar questionado:

Esse quinto postulado é bem estranho não? Ele foi reescrito de diversas formas, e uma das mais conhecidas é: "por um ponto fora de uma reta pode-se traçar uma única reta paralela à reta dada" Aparecer uma imagem animada representando a ideia.

Aparecer o avatar explicando:

Este postulado trouxe grandes repercussões entre os matemáticos de diversas épocas, e um fato bem interessante foi destacado por Proclo, um grande comentarista de Os Elementos, em meados do século $\mathrm{V}$.

Aparecer a imagem de Proclo.

Ele percebeu que as 28 primeiras proposições do trabalho (que são 465 no total) são provadas sem usar este postulado, sendo que algumas seriam facilmente demonstradas se o quinto postulado fosse utilizado. Desta forma, é possível concluir que até Euclides tentava "evitar" o uso deste postulado.

Aparecer o avatar explicando:

Dentre os matemáticos que tentaram provar o quinto postulado é possivel citar: Ptolomeu I (aparecer a foto).

O próprio Proclo (aparecer a foto).

O árabe Nasis Eddin All Tusin (aparecer a foto).

John Wallis (aparecer a foto).

O padre jesuíta Girolamo Saccheri (que foi o primeiro a publicar) (aparecer a foto). 
Joahnn Heinrich Lambet (aparecer a foto).

Adrien Marie Legendre (aparecer a foto).

entre tantos outros.

Aparecer o avatar explicando:

Todavia nenhum delesconseguiram demonstrar este postulado, porém séculos mais tarde (entre os séculos XVIII e XIX) alguns matemáticos compreenderam que o quinto postulado de Euclides além de não poder ser provado, poderia ser negado sem que contradições acontecessem, neste episódio ganha destaque Nikolay Ivanovich Lobachevsky (1792-1856) (aparecer a foto), János Bolyai (1802-1860) (aparecer a foto) e Cal Friedrich Gauss (1777-1855) (aparecer a foto).

Aparecer o avar explicando:

Os quais descobrem que ao negar ou substituir o quinto postulado por outro surgiria uma nova geometria tão válida quanto a de Euclides.

O próprio Lobachevsky propos que este postulado fosse substituído pelo seguinte postulado:

Aparecer no quadro:

"Existe uma reta $r$ e um ponto $P$ que não pertence a $r$ tal que por $P$ passa ao menos duas retas paralelas à reta $r$ ".

Aparecer a imagem da pseudoesfera.

Assim surgiu uma geometria chamada de geometria hiperbólica, na qual leva em consideração uma superfície não plana como mostra a imagem.

Aparecer a foto de Riemann.

Já um matemático alemão que se chamava Georg Friedrich Bernhard Riemann (18261866), propôs que o quinto postulado fosse substituído pelo seguinte:

Aparecer no quadro:

"Dada uma reta $L$ e um ponto $P$ não pertencente a $L$, não existe reta paralela a $L$ passando por $P$ ". Aparecer a imagem da esfera.

Assim deu-se forma uma outra geometria não euclidiana, chamada de geometria elíptica, sendo esta desenvolvida sobre a superfície de uma esfera.

Aparecer o avatar explicando:

Desta forma entendemos que foi a negação ou a substituição de um postulado que possibilitou a criação das geometrias não euclidianas. Assim, ficou definido que:

Aparecer no balão:

Uma geometria é chamada de não euclidiana quando ela nega pelo menos um dos postulados de Euclides.

Aparecer o avatar explicando:

As geometrias hiperbólica e elíptica são apenas exemplos de geometrias não euclidianas, ou seja, existem outras, porém foi com elas com que tudo começou.

Fonte: Os Autores

O vídeo foi feito em forma de animação, a qual foi elaborada a partir do software Power Point utilizando os recursos de efeitos visuais de entrada e saída, ênfase e transição, de maneira que dessem o efeito de movimento do avatar, entre outros elementos que podem ser vistos no vídeo. Alguns objetos foram programados para aparecer ou sair da apresentação no momento desejado, e por isso o roteiro foi muito importante. A figura a seguir mostra o processo de animação: 
Figura 2 - Animação das imagens no Power Point

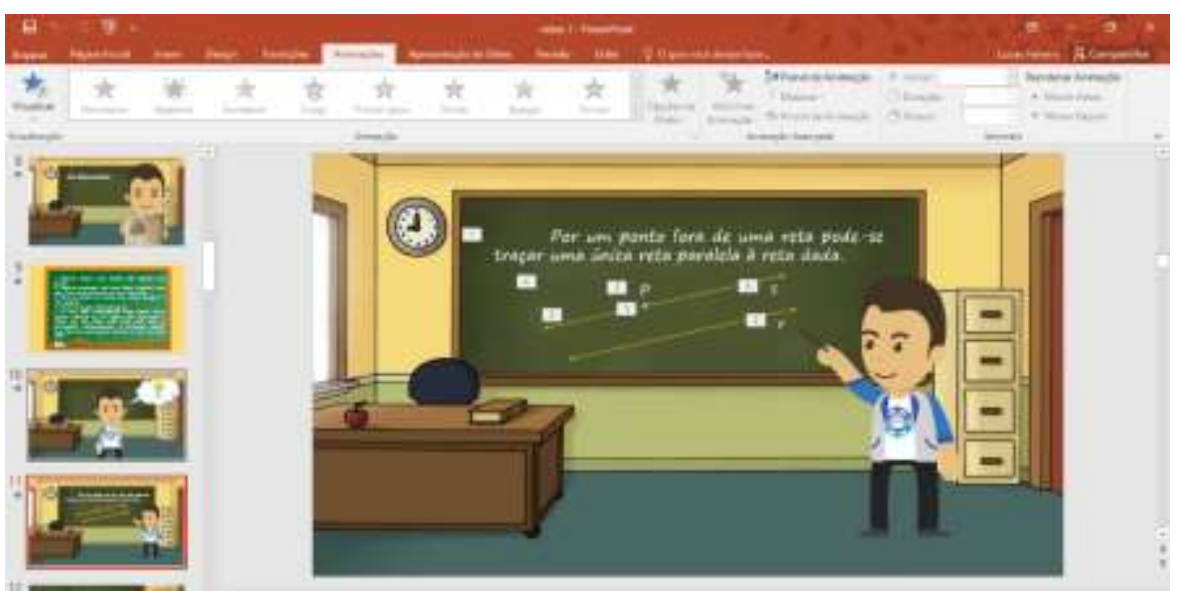

Fonte: Os Autores

Optou-se pela utilização de um avatar ${ }^{4}$, pelo aspecto visual, já que ele representa a ideia das Geometrias Não Euclidianas. Como é possível perceber na Figura 2, ele traz em sua camiseta um logotipo que remete a tais geometrias, além disso, é possível inserir outros elementos, como ambientes e posições variadas, que dão vida ao vídeo.

\section{Revisão e elaboração}

Nesta fase, é necessário moldar as imagens e fazer as correções necessárias, além disso:

Outra coisa a se fazer nessa etapa é a seleção musical que fará parte da trilha sonora do vídeo como background. Um cuidado a ser tomado é a seleção de uma música para cada etapa, atentando para seu tamanho: 10, $30,45,60$ segundos ou mais, se necessário. É importante escolher um acorde com a música do filme, possivelmente, uma música sem palavras, para não sobrepor-se à voz do narrador ou do ator/palestrante/professor (MACHADO; MENDES, 2013, p. 97).

No que diz respeito ao vídeo elaborado, a escolha das músicas (trilhas) foi uma etapa em que dificuldades foram encontradas, pois era necessário tomar cuidado com essa escolha que deveria ser apenas trilhas livres de direitos

${ }^{4}$ O avatar foi criado pelo aluno Elias de Moraes Fernandes, sob orientação do Prof. Dr. Alexandre Rossi Paschoal, dentro do grupo de pesquisa "Laboratório de Jogos Digitais: Desenvolvimento de Jogos e/ou Aplicativos para Mobile \& Cia", coordenado e desenvolvido por tal professor na Universidade Tecnológica Federal do Paraná - campus Cornélio Procópio. 
autorais, ou seja, aquelas que já estão no domínio público ou trilhas brancas ${ }^{5}$. Por isso, optou-se por trilhas brancas por ter melhor qualidade e se ajustarem melhor ao que era pretendido, as quais são encontradas de diversos tamanhos, como 1 minuto, $30,20,15$ e 10 segundos.

\section{Filmagem}

"Só agora, neste momento, procedem-se as filmagens. Devem aderir plenamente ao que está previsto. Isso apenas permite que o vídeo tenha um bom desenvolvimento" (MACHADO; MENDES, 2013, p. 97).

Em relação ao vídeo produzido, esta etapa foi desenvolvida após a conclusão das montagens das animações, e se deu a partir do software Camtasia Studio (Figura 3), que é um aplicativo que permite a gravação e edição de vídeos a partir da captura da área de trabalho do Windows, ou seja, ele permite gravar toda atividade realizada na tela do computador, além da narração que é feita simultaneamente a captura.

Figura 3 - Gravação das imagens no Camtasia Studio

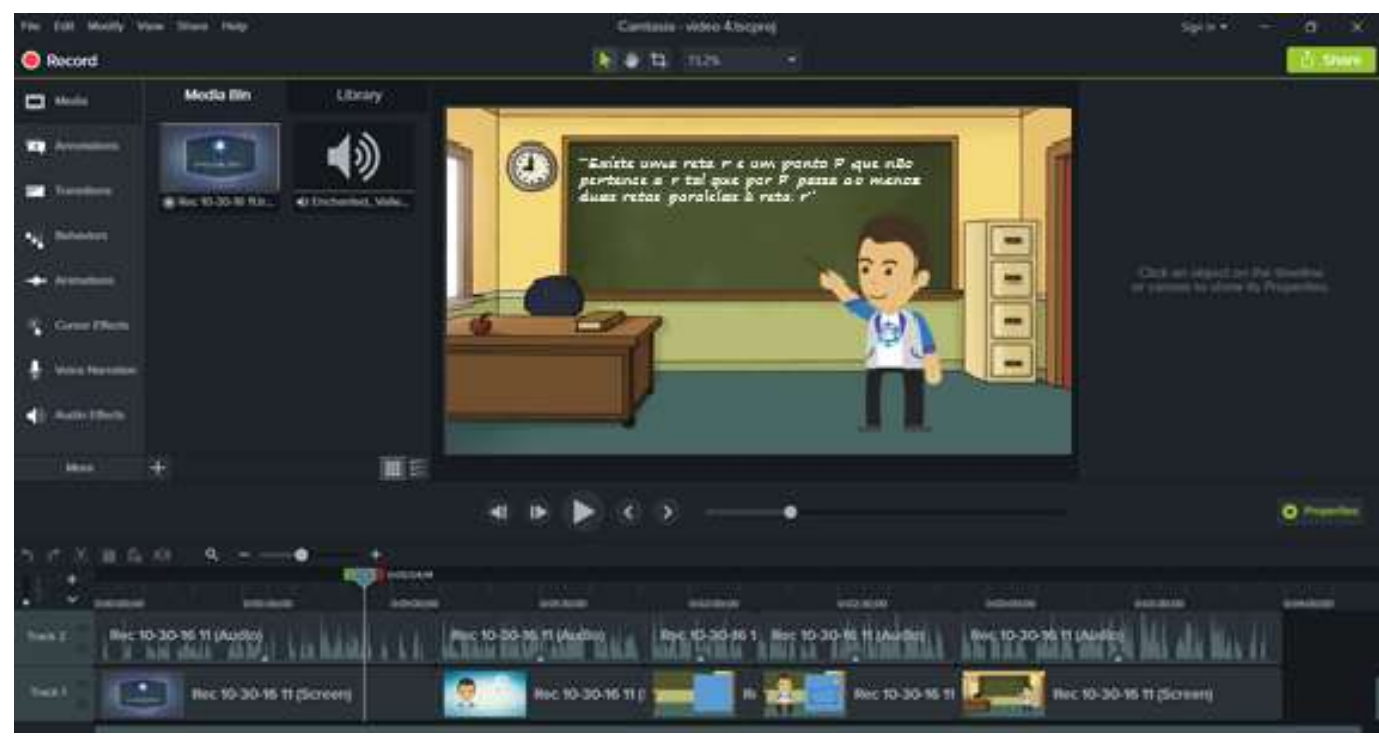

Fonte: Os Autores

\footnotetext{
${ }^{5}$ São trilhas sonoras livres, que não é necessário pagar pela sua utilização.
} 


\section{Edição Preliminar}

Depois da gravação, os vídeos devem passar por um processo de edição e montagem que "é o conjunto do vídeo, incluindo os efeitos e transições, que ajudam a linha narrativa do vídeo que está sendo feito. Nesta fase procedem-se cortes em partes de cada cena do vídeo, aparando os excessos preliminares, intermediários e finais" (MACHADO; MENDES, 2013, p. 97).

Nesta etapa também deve ser feita a inserção do brackground, que é a música de fundo, que de acordo com Machado e Mendes (2013, p. 98): "não deve haver espaço com músicas em altura de som maior do que a voz do narrador, para não prejudicar o entendimento do texto. Deve haver sincronia entre imagens e sons para que o público possa relaxar e desfrutar do conteúdo do vídeo".

\section{Edição final}

São os ajustes finais de sincronias, cortes ou prolongamentos de imagens ou áudio, bem como a maneira de como escolherá salvar seu arquivo. Se desejar publicar na internet, rodar em DVD ou outra mídia, atenção para o formato do vídeo. Isso é importante porque o tamanho final do arquivo deve ficar de acordo com as necessidades. Um vídeo que será compartilhado na internet não precisa da mesma resolução de um vídeo que será apresentado em um evento ou gravado em um CD (MACHADO; MENDES, 2013, p. 98).

Antes destas duas etapas de edição (preliminar e final) serem realizadas, assistiu-se o vídeo para identificar se havia algo para ser corrigido ou fazer alguns cortes necessários. Além disso, ambas as etapas foram realizadas com os recursos do software Camtasia Studio, que em termos de edição oferece a função de fazer zoom, adicionar áudio, criar efeitos de transição e limpar o som de ruídos. Com ele também é possível finalizar o vídeo em diversos formatos comuns de multimídia: avi, swf, exe, flv, wmv, gif animed, entre outros.

Assim conseguimos produzir, editar e finalizar a produção do vídeo proposto, 0 qual está disponível em https://www.youtube.com/watch?v=egjKgzx7fLk\&t=4s. 


\section{Algumas considerações}

A partir deste processo de produção de vídeos didáticos baseados na História da Matemática, é possível dizer que tal prática pode contribuir para uma aula mais dinâmica e prazerosa por parte do aluno. Como destaca Machado e Mendes (2013) o vídeo poder ser um instrumento de ativação da aprendizagem em sala de aula devido a suas potencialidades, dentre elas "favorece a conexão entre as componentes intuitiva, algorítmica e formal" proposta por Mendes (2010, 40).

No que diz respeito a nosso trabalho, foi possível perceber que as técnicas utilizadas e propostas para produção de vídeos didáticos baseados na História da Matemática são de possível execução. Além disso, essa prática não exige recursos tecnológicos avançados, e que, por essa razão, pode ser desenvolvida por professores em suas aulas. Pelo exposto, percebe-se que a seleção de material histórico, que, de forma didática, pode possibilitar a produção de vídeos, é algo possível. Aqui, foi encontrado nos saberes docentes um potencial para se selecionar episódios históricos a partir de uma reconstrução histórica já realizada.

A partir deste trabalho, buscou-se mostrar uma estratégia para se elaborar vídeos didáticos de História da Matemática, de modo que os professores tenham subsídios que Ihes permitam produzi-los e utilizá-los, de tal modo que a História da Matemática seja inserida em sala de aula e que, assim, este recurso didático possa desempenhar suas contribuições para a formação dos alunos.

\section{Referências}

ARAMAN, E. M. O. Contribuições da história da matemática para a construção dos saberes do professor de matemática. 2011. 228 f. Tese (Doutorado em Ensino de Ciências e Educação Matemática) - Centro de Ciências Exatas, Universidade Estadual de Londrina. Londrina, 2011.

BALDIN, Y. Y. Uso de tecnologia como ferramenta didática no ensino integrado: Uma forma de educação continuada para professores de nível básico. In: CARVALHO, L. M.; 
FOSSA, J. A.; GIRALDO, V.; MOURA, C. A. de; NORONHA, H. (Org.) História e tecnologia no ensino da matemática, vol. 2. Rio de Janeiro: Ciência Moderna, 2008.

BARBOSA, L. N. S. C. de. Uma reconstrução histórico-filosófica do surgimento das geometrias não euclidianas. 2011. 58 p. Dissertação (Mestrado em Ensino de Ciências e Educação Matemática) - Universidade Estadual de Londrina. Londrina, 2011.

BICUDO, I. Os Elementos/Euclides. Trad. Irineu Bicudo. São Paulo: Editora UNESP, 2009.

BISSI, T. Álgebra e história da matemática: uma proposta de ensino a partir da matemática do Antigo Egito. In: ENCONTRO BRASILEIRO DE ESTUDANTES DE PÓS-GRADUAÇÃO EM EDUCAÇÃO MATEMÁTICA, XIX, 2015. Juiz de Fora. Anais... Juiz de Fora: Universidade Federal de Juiz de Fora. 2015.

http://www.ufjf.br/ebrapem2015/files/2015/10/gd2_tiago_bissi.pdf. Acesso em: 12 mar. 2016.

BOGDAN, R.; BIKLEN, S. Características da investigação qualitativa. In: Investigação qualitativa em educação: uma introdução à teoria e aos métodos. Porto, Porto Editora, 1994. p. 47-51.

BRASIL. Parâmetros Curriculares Nacionais: Matemática. Secretaria de Educação Fundamental. Brasília: MEC/SEF, 1997.

BRITO, A. J. Geometrias não euclidianas: um estudo histórico pedagógico. 1995. 187 p. Dissertação (Mestrado em Educação) - Faculdade de Educação, Universidade Estadual de Campinas, Campinas, 1995.

CARVALHO, A. M. P. de; GONÇALVES, M. E. R. Formação continuada de professores: o vídeo como tecnologia facilitadora da reflexão. Cadernos de Pesquisa, dez. 2000.

Disponível em: <http://www.scielo.br/scielo.php?script=sci_arttext\&pid=S0100-

5742000000300004 \&lng=pt\&nrm=iso\&tlng=pt>. Acesso em: 12 jul. 2007.

CHAQUIAM, M. História da matemática em sala de aula: proposta para integração aos conteúdos matemáticos. São Paulo: Livraria da Física, 2015. (Série História da Matemática para o Ensino).

COSTA, L. F. Diálogo entre a história da matemática e as novas concepções do ensino de matemática: os recursos audiovisuais na formação de professores. In: IV COLÓQUIO INTERNACIONAL EDUCAÇÃO, CIDADANIA E EXCLUSÃO: DIDÁTICA E AVALIAÇÃO, 2015, Rio de Janeiro. Anais... Rio de Janeiro: 2015.

CURY, H. N.; MOTTA, C. E. M. História e estórias da matemática: uma entrevista com Heron nos dias atuais. In: CARVALHO, L. M. et al (Org.). História e tecnologia no ensino da matemática. v. 2. Rio de Janeiro: Ciência Moderna, 2008.

DEIXA, G. V.; SALVI, Rosana F. Dificuldade dos professores em exercício no uso da história da matemática como alternativa didáctica para o ensino da matemática. Revista Científica da UEM: Série Ciências da Educação, v. 1, n. 1, p. 63-76, 2014. 
FAUVEL, J. MAANEN, J. V. Introduction. In: FAUVEL, J. MAANEN, J. V. (Ed.). History in mathematics education: the ICMI study. Dordrecht: Kluwer Academic Publishers, 2000. p. 6-18.

GAUTHIER, C. Por uma teoria da Pedagogia, pesquisas contemporâneas sobre o saber docente. Rio Grande do Sul: Unijui, 2006.

GROENWALD, C. L. S. Perspectivas em Educação Matemática. Canoas: Ulbra, 2004.

HANSEN, V. L. Everlatig Geometry. In: MAMMANA, Carmelo; VILLANI, Vinicio (Ed.). Perspectives on the teaching of geometry for the 21st century: an ICMI study. Dordrecht, Boston, London: Kluwer Academic Publishers, 1998.

JANKVIST, U. T. A categorization of the "whys" and "hows" of using history in mathematics education. Educational Studies in Mathematics, Dordrecht, n. 71, p. 235261, 2009.

KATZ, V. J. A história da matemática: uma introdução. Lisboa: Fundação Calouste Gulbenkian, 2011.

MACHADO, B. F. Vídeo-aula de história da matemática: uma possibilidade didática para o ensino de matemática. 144 f. 2011. Dissertação (Mestrado em Ensino de Ciências Naturais e Matemática) - Universidade Federal do Rio Grande do Norte. Centro de Ciências Exatas e da Terra. Natal, 2011.

MACHADO, B. F.; MENDES, I. A. Vídeos didáticos de história da matemática: produção e uso na educação básica. São Paulo: Editora Livraria da Física, 2013.

MENDES, I. A. A investigação histórica na formação de professores de matemática. Revista Cocar, Belém, v. 4, n. 7, p. 37-48, jan./jun. 2010.

MENDES, I. A.; CHAQUIAM, M. História nas aulas de matemática: fundamentos e sugestões didáticas para professores. Belém: SBHMat, 2016.

MORÁN, J. M. O vídeo na sala de aula. Comunicação e Educação, São Paulo, v. 2, p. 27-35, jan./abr. 1995.

NOBRE, S. R. Introdução histórica às geometrias não euclidianas: uma proposta pedagógica. Belém: SBHMT, 2009. (Coleção História da Matemática para professores).

OLIVEIRA, A. J. S. O ensino e a aprendizagem de função exponencial em um ambiente de modelagem matemática. 2013. 96 f. Dissertação (Mestrado em Matemática) - Universidade Federal Rural Do Semiárido, Mossoró, 2013.

PARANÁ. Diretrizes curriculares da educação básica de matemática. Curitiba: SEED, 2008. disponível em: http://www.nre.seed.pr.gov.br/irati/arquivos/file/matematica.pdf>. Acesso em: 15 fev. 2017. 
RIBEIRO, R. D. G. L. O ensino das geometrias não euclidianas: um olhar sob a perspectiva da divulgação científica. 2012. 102 p. Dissertação (Mestrado em Ensino de Ciências e Matemática) - Faculdade de Educação, Universidade São Paulo, São Paulo, 2012.

TARDIF, M. Saberes docentes e formação profissional. Rio de Janeiro: Vozes, 2013.

TARDIF, Maurice; GAUTHIER, Clermont. O saber profissional dos professores fundamentos e epistemologia. In: SEMINÁRIO DE PESQUISA SOBRE O SABER DOCENTE, 1996, Fortaleza. Anais... Fortaleza: UFCE, 1996. 